\title{
The role of numerical modeling in scientific fire investigation
}

\author{
Marius Cornel Șuvar ${ }^{1 *}$, Laurențiu Munteanu ${ }^{1}$, and Zoltan Vass ${ }^{1}$ \\ ${ }^{1}$ National Institute for Research and Development in Mine Safety and Protection to Explosion - \\ INSEMEX Petroșani, 32-34 General Vasile Milea Street, Petroșani, Romania
}

\begin{abstract}
Fire risk is perhaps the most common risk in the category of special emergencies, being a phenomenon that affects important areas of economic and social life, such as buildings, industrial facilities, public spaces, forests, crops, or transportation. Scientific investigation of fires is constituted as a set of organized actions, of technical nature, undertaken to determine the causes that led to the occurrence of fires, the source of ignition, and the circumstances that favored the event.

Numerical fire modeling is a widely recognized and accepted tool for analysis in fire research. The results of the investigation carried out on-site are compared with the results of fire evolution obtained by computer simulation, using numerical models based on known input data, to verify different hypotheses regarding the cause of the fire. The advantages over experimental methods are expressed by low costs and substantial time savings. Moreover, several simulations can be run simultaneously, for different scenarios of the event or the analysis of different consequences.

The paper presents the main advantages that numerical modeling by FDS methods brings in the technical-scientific expertise of fire, with implications in the data analysis, development, and testing of hypotheses, respectively in the selection process of the final hypothesis. words.
\end{abstract}

\section{Introduction}

Fire is a phenomenon with special social implications. Every year, worldwide, fires cause tens of thousands of life losses, hundreds of thousands of injuries and huge material losses. At the same time, the fire causes more loss of life and property than all-natural disasters.

Investigating the causes of a fire or explosion is a complex process, which requires investigators several specific, multidisciplinary abilities and knowledge, and implies the use of scientific notions and advanced technical equipment. This process consists of organizational measures and actions, which include specific methods, procedures and activities to establish precisely the causes and circumstances that contributed to the occurrence of the fire or the event followed by the fire.

The methodology used to investigate fires must be based on the use of systematic approaches, paying particular attention to all relevant details. The use of these basic rules will often lead to the discovery of new data, factual information, which may require

*Corresponding author: marius.suvar@insemex.ro 
reconsideration of conclusions. With some exceptions, the recommended methodology for investigating these events is to determine and establish in the first instance the initial outbreak or outbreaks, followed by the investigation of the causes, favorable circumstances, environmental or other conditions during the phenomenon, respectively the mechanism by which the source of ignition, substance or combustible material and the oxidizing agent (oxygen) may have formed the conditions necessary for the occurrence of the initial flame.

The recommended approach in researching such events is the one based on the scientific method, specific to the field of physical sciences. The scientific method, in the case of fire investigation, consists of a series of specific requirements, organized in a logical sequence, each being characterized by activities and processes of an engineering and scientific nature. Thus, the scientific approach begins with identifying the problem, followed by defining it, collecting data, analyzing data and information, developing hypotheses by inductive reasoning, testing hypotheses - deductive reasoning, then ending after selecting the final hypothesis. The compilation of data and the analyses of all factual facts should be accomplished objectively, truthfully, without any expectation bias, preconceptions and prejudice [1].

An important role in the last stages in application of the scientific method, especially in the phase of elaboration of hypotheses and their testing, is played today by the use of computer modeling of fire/explosion. The main purpose of these simulations is to introduce and use mathematical and physical notions to explain the materials' fire behavior and the dynamics of fire [2-3].

Creating the virtual model for the geometry of the space involved in the event and running computer simulations for various fire scenarios, lead to a better understanding of the combustion processes and fire dynamics, providing important details on the development over time, the occupants' exposure risk, the assessment of survival possibilities, as well as in the analysis of combustible materials and post-event indicators [4] .

\section{Materials and methods}

\subsection{Scientific method in fire investigation}

The origin of a fire is one of the most important hypotheses that the investigator develops and tests, in his scientific approach. The scope of determining the fire source is to identify the location at which the fire began, in a three-dimensional coordinate system.

This process involves the coordination of information from different sources:

- the analysis of observations reported by witnesses, present at the time of the event;

- analysis of electronic data, including security camera records, alarm system activation $\operatorname{logs}$, different reports written by the firefighter team, etc;

- analysis of the fire effects and the fire patterns, laboratory test for the evidences taken from the scene of the fire, the observation of the investigators, following the on-site investigation;

- the analysis of fire dynamics - the physics and chemistry of fire ignition and growth, as well as the interaction between the fire and the building's system.

The overall methodology for fire investigation is the scientific method, as described in introduction. This approach consists in a number of stages, in a logical hierarchy, with the scope of developing hypotheses and then, testing the hypothesis or hypotheses. This hypotheses must be considered as working hypotheses, which can be later discarded, revised or expanded, as new data and evidences are collected and new analyses are applied. The process is repeated iteratively, each time new information regarding the case appears [1],[2], $[5]$. 


\subsection{Computer fire modeling and FDS (Fire Dynamics Simulator)}

Computer fire modeling use complex mathematical tools and equations to analyze the fire and life safety in buildings, regardless of their destination. Modern computer fire models are capable of many things, such as:

- Predicting fire ignition, growth and development;

- Evaluating occupant safe evacuation;

- Analyzing smoke and fire control systems, with prediction of detectors activation time;

- Explaining fire mechanisms and providing plausible timeline of events.

Since the inception of computer fire models, numerous governmental, university and private laboratories have been assisting with the progression and development of the models to better ensure that the mathematical equations reliably represent real-world fire behavior.

Computer modeling is faster and more economical compared to real-scale experimentation, allowing the introduction of variable values for the parameters considered and the analysis of various consequences [2]. At the same time, through simulations, relationships can be established between the post-fire indicators and the sequence of stages specific to the evolution of fire [6].

There are many computer models: models of heat transfer, models for structural analysis, models for fire extinction system analysis and models for human evacuation. More advanced are the models of thermodynamic analysis used in fire safety, which can be specialized (e.g., in smoke movement, people evacuation), zone models (FIRST -Fire Simulation Technique, CFAST - Consolidating Fire and Smoke Transport, etc.) or field models (FDS - Fire Dynamics Simulator, SOFIE - Simulation of Fire in Enclosures, etc.). The Computational fluid dynamics (CFD) model is also known as field models. Field models separate a geometry into hundreds to thousands of tiny rectangular (grid) or calculation cells based on user inputs. Field models are more calculation intensive than their zone model counterparts. These models calculate each cell using higher level mathematics to specifically relate energy transfer and flow of fluids to each other. The basic laws of mass, momentum, and energy conservation are applied in each cell and balanced with all adjacent cells [7]. After each second of the simulation has been calculated for every individual cell, the data is ready for visualization, using application like Smokeview or Thunderheadeng PyroSim Results. From this category, FDS is the most advanced and more used field computational model, this being also the main reason for his choice for the computer simulation made in the case study presented in the next section of the paper.

\section{Results and discussions}

To highlight the importance of using numerical modeling in the scientific investigation of fire/explosion type events, we will present a case study based on a real event, which occurred a few years ago, in Romania. Following a violent fire that affected a building located in the urban area, destined for a restaurant, the Prosecutor's Office attached to the High Court of Cassation and Justice requested INCD INSEMEX Petroșani, by ordinance, the elaboration of technical expertise, whose report will be established part of the complex forensic expertise report.

The affected building was a construction made on a light structure, made of wood, with ground floor and attic, attached to a house-type building. On the ground floor there is a consumption lounge with tables, bar, kitchen, bathrooms and various annexes, and on the attic, a restaurant lounge with an area of 50 square meters, locker room and a bathroom. The structure of the building where the restaurant exists was as follows: wooden pillars and beams, the floor between the ground floor and the attic supported by wooden beams, plated 
at the top with PFL boards, PVC foil, then laminate flooring, and at the bottom plated with oriented strand boards (OSB), mineral wool and tin sheets, the roof being made of poles, beams, fir wood rafters, OSB boards, mineral wool, tar paper and tin roofing sheets. The access to the 1st floor (attic of the construction) was made on the stairs, where there was the locker room, the customer room (the lounge room) and the passage area to the social group (fig. 1).

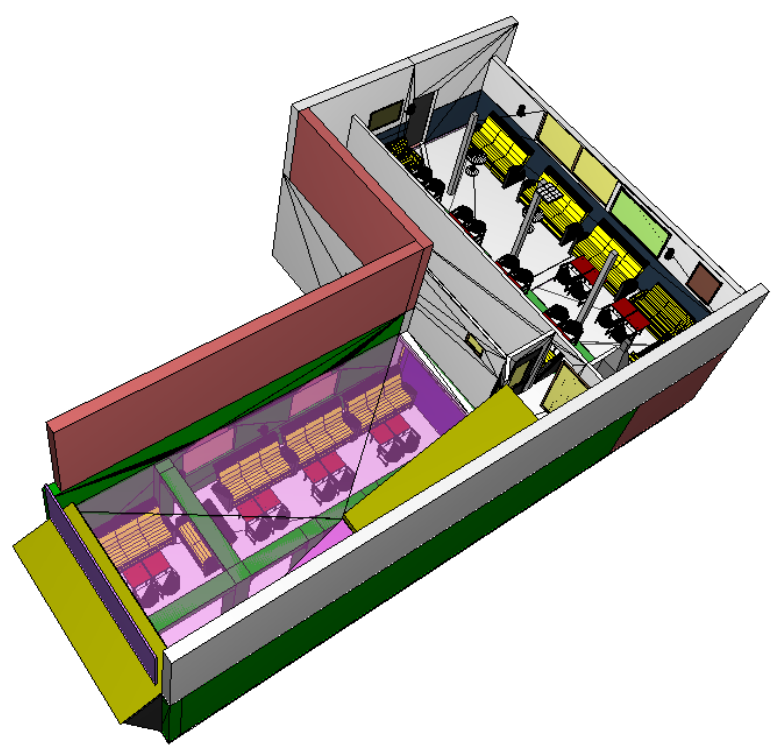

Fig. 1. The geometry of the virtual model of the analyzed building, made in FDS, using the PyroSim user interface.

Following the on-site findings, the analyzes performed and the technical-scientific reasoning, it became clear that the ignition source and the first materials set on fire (initial outbreak) were located in the area of the eastern wall of the restaurant, near a brick chimney, at a level higher than the hot gases evacuation connection, corresponding to the bread oven placed in the kitchen (fig.2).

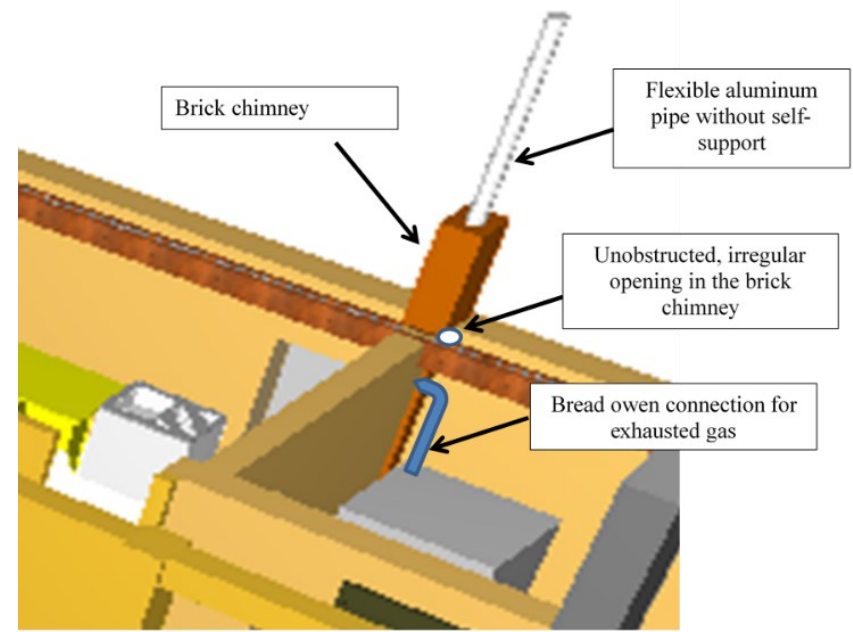

Fig. 2. The fire ignition source for the presented case 
One of the major difficulties of the post-event investigation in determining the initial outbreak and the causes that favored the fire was to establish the exact source of ignition. Following the analysis of the event's footprint and the interpretation of data from various sources, both those provided by the competent authorities and those taken at the crime scene by the INSEMEX team, the following potential sources of ignition were retained for analysis: sources of thermal nature (incandescent objects and hot gases), electrical sources (short circuit) and deliberate fire (Arson effect). The probability of the last two hypotheses, resulting from the analysis of all available information, of the laboratory tests carried out on the onthe-spot evidence and of the witness statements present in the case file, was very low so that the plausible source of ignition was considered to be of thermal nature: incandescent bodies and hot gases. Contact between combustible substances and materials with incandescent bodies (incandescent particles from burning coals, embers, red hot pipes, etc.) can lead to the ignition of materials in the presence of hot gases.

For the considered case, there were taken into analyzing the following potential sources of ignition:

a) The incandescent flour dust particles and hot gases from the bread oven;

b) The incandescent particles and hot gases from the coals or embers used in the grill.

In the case of the first potential ignition source, the occurrence of incandescent particles of flour dust is easily achieved because in the oven there are gas burners, both flames and flue gases having temperatures of approx. $850^{\circ} \mathrm{C} \div 900{ }^{\circ} \mathrm{C}$, higher than the minimum ignition temperature of the flour powder (approx. $458{ }^{\circ} \mathrm{C}$, in form of a cloud, respectively approx. $400{ }^{\circ} \mathrm{C}$, in layered form).

The mechanism of occurrence of incandescent flour dust particles, in the route of the hot flue gas on the exhaust pipe from the bread oven, is the following:

- The penetration of a significant quantity of flour, with the introduction of the breads in the oven, coming from coating the wooden pallet with which the pieces of bread are placed into the oven;

- The entrainment of flour dust particles by exhausting gases from the furnace gas burners on the connection route, a brick chimney casing and then, through the flexible aluminum pipe, being discharged into the atmosphere (fig. 3);

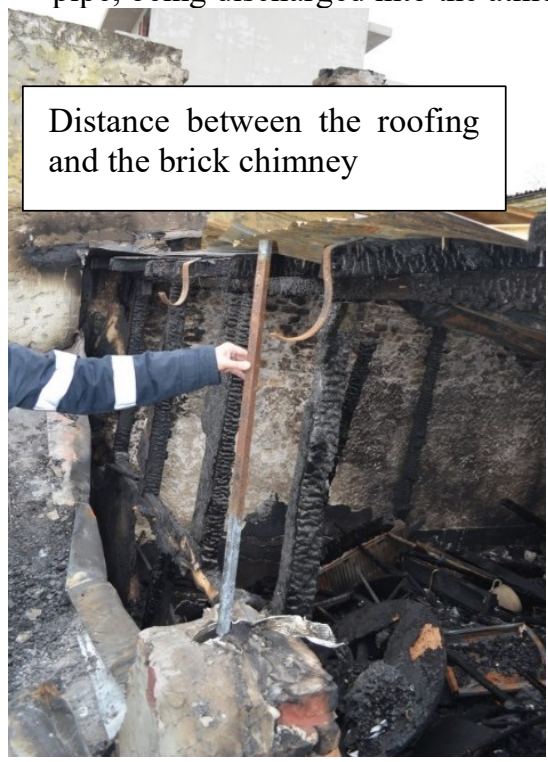

Fig. 3. Distance between the roofing and the brick chimney

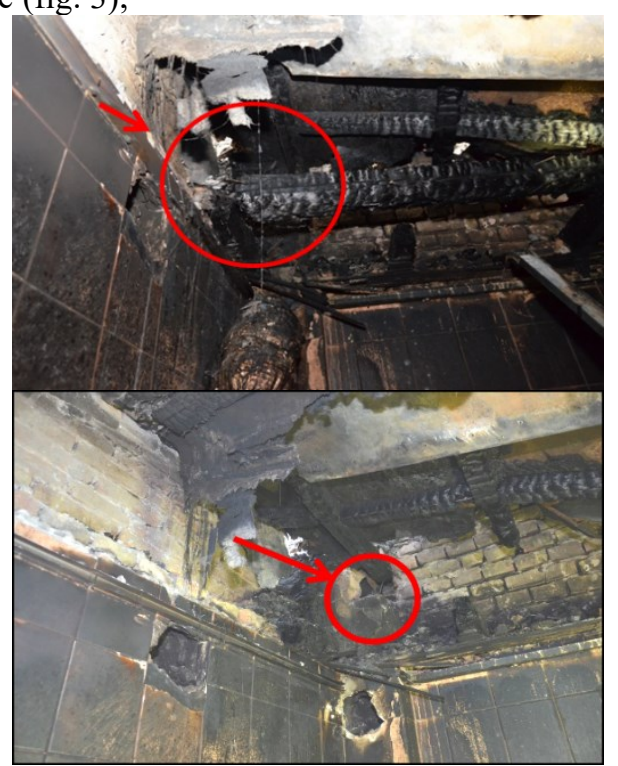

Fig. 4. The unobstructed opening in the brick chimney, near the floor supporting wood beam 
- Some particles are "ignited" in the furnace near the flames and exhausted as ashes, others are circulated only preheated by the rising currents created in the connection pipe, chimney and flexible aluminum piping and ignite, become incandescent along the way, their ignition due to hot gases products by burning methane gas inside the furnace;

- The unobstructed opening of the brick chimney (fig. 4) allows some of the hot flue gases as well as the incandescent particles of flour dust to come into intimate/direct contact with the highly flammable resinous material of the floor supporting beam. In addition, if the flexible aluminum tube, without its load-bearing capacity, placed in extension of the brick chimney, would have changed its initial position (for example under the action of the wind), it would have reduced the free section of the tube. In this way, the volume of flue gases exhausted through the flexible aluminum tube would have decreased, leading to an increase in the flow of flue gases and particles (incandescent and/or burned) discharged through the free opening in the brick chimney in the vicinity of the wooden beam/material.

The second potential source of ignition consists in the appearance of incandescent particles from charcoal used in the grill. During the process of coal burning (charcoal), to prepare grilled menus, devices are used to activate the embers. Thus, incandescent particles are generated, which due to the depression made by the centrifugal fan connected through a flexible aluminum tube to the chimney corresponding to the grill hood, are aspirated and evacuated into the atmosphere at the level of the wall with a window, placed at the 1 st floor of the restaurant.

According to the findings on the fire scene, the footprint of the fire indicates the strong burning of wooden beams and walls, from the area above the kitchen, from the chimneys to the locker room. The scenarios of occurrence and development of the fire simulated with the help of the PyroSim software package targeted the two hypotheses described above, which highlight as potential initial outbreaks:

a) The wooden beam which supports the ceiling separating the ground and the $1^{\text {st }}$ floor, near the unobstructed hole/opening identified at the fire scene in the brick chimney, at a higher level than the bread oven connection;

b) The extruded polystyrene with which the eastern wall of the restaurant floor was covered, in the vicinity of the brick chimney (the polystyrene being embedded in the plaster/mortar material of the chimney, in the vicinity of the centrifugal fan outlet.

In the stage of hypothesis testing, specific to the scientific method of fire investigation, given the difficulty of establishing the mechanism of fire ignition and development, computer simulations were used, starting from the two possible scenarios.

The first scenario involves the fire ignition from the wooden beam supporting the floor between the ground floor and the first floor, near the hole / unobstructed opening identified at the fire scene in the brick chimney, at a higher level than the bread oven connection (fig. $5,7)$. The free opening in the chimney allowed some of the flue gases as well as the incandescent flour dust particles to come into intimate contact with the easily flammable resinous material of the floor support beam. Given the fuel support of the building: the structure, the walls, floor, roof, decorations (made of wood, plastic, textile, PVC, etc.) once the initial outbreak occurred, the fire spread quickly, covering initially the entire $1^{\text {st }}$ floor, and then it extended to the ground floor, causing important losses (3 human deaths and multiple material losses). 


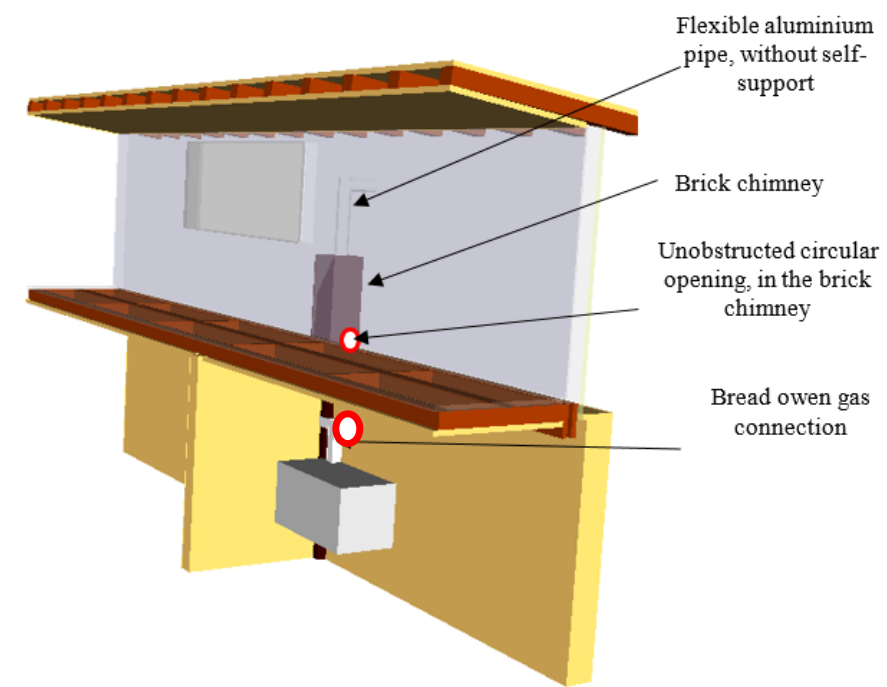

Fig. 5. Building section (ground floor + attic), eastern wall. Hypothesis (a)

In the second simulated scenario, the fire starts from the evacuation of hot flue gases and incandescent dust particles, as well as by the random orientation, caused by the wind, of the flexible aluminum tube, without load-bearing capacity, installed in the extension of the brick chimney. These particles could have come into direct contact with the extruded polystyrene from which the thermal insulation of the building was made, setting it on fire (fig. 6, 8).

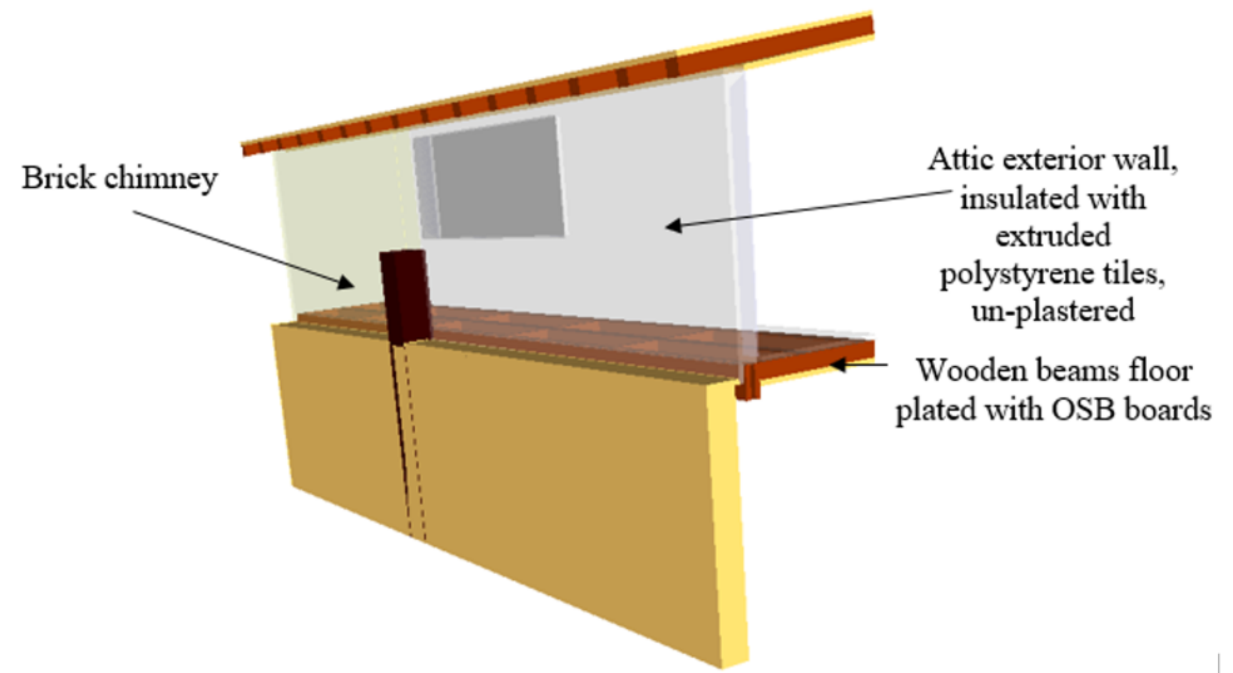

Fig. 6. Building section (ground floor + attic), eastern wall. Hypothesis (b)

It should be noted that in both cases, the incandescent particles came into direct/intimate contact with the combustible material, generating in the first phase its smoldering combustion and later, either due to activating elements (air currents, additional heat input) or due to the slow accumulation of heat in the material, the transformation of smoldering combustion into flame combustion.

Comparing the two hypotheses, it turned out that both are plausible. The choice of a single hypothesis, with the highest level of probability, involves a laborious process, which must 
take into account all the evidence and documents provided, the statements of witnesses, the footprint of the fire and all the clues that can be obtained through research at the fire scene.
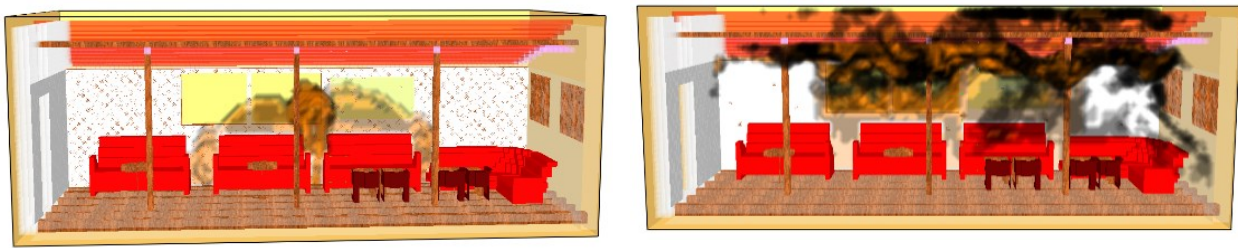

Fig. 7. The ingress of flames from the burning beam inside the first floor, followed by the fast fire development and lighting of furniture, by thermal radiation and hot gases - Hypothesis (a)
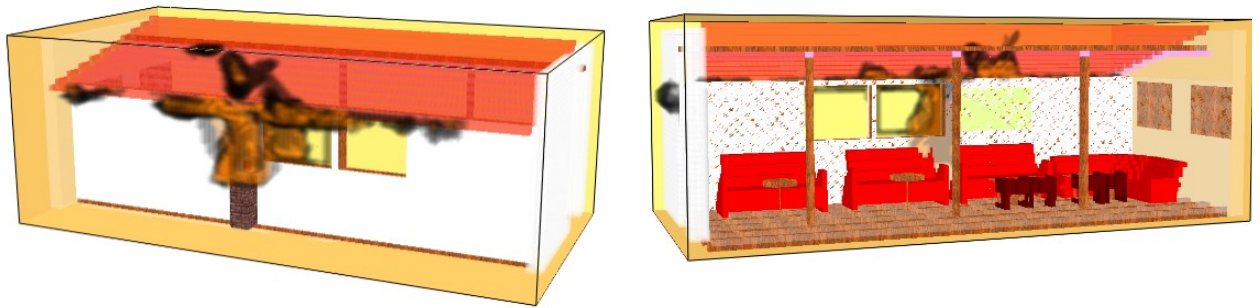

Fig. 8. Ignition of the eastern wall covered with extruded polystyrene, followed by the spread of fire through the window, inside the attic and lighting the furniture near the wall- Hypothesis (b)

Often, in this stage of selecting the final hypothesis, computer modeling of the fire is used to supplement the information obtained, to explain certain aspects or details of the fire mechanism, so that the probability of a hypothesis can be demonstrated with a high level of confidence. The accepted and peer-reviewed methodology for using computer fire models is to provide a range of variables to evaluate both the sensitivity of the model and ensure that the variables that are not specifically known are accounted for within the series of models.

In the present case, using the FDS software and the specialized program PyroSim, it emerged that hypothesis (a) fully explains the rapid evolution of the fire inside the restaurant and the generation of thermal effects and gases that surprised the victims in the locker room on the $1^{\text {st }}$ floor.

Comparing the two simulated event scenarios, based on the interpretations performed on the temperature and carbon monoxide diagrams recorded by the virtual measuring devices positioned at key points of the model, given the higher values recorded in scenario 1, it could be concluded the fact that the event was generated by the lighting of the fir wood beam supporting the slab between the ground floor and the first floor, near the unobstructed opening (identified at the fire scene in the brick chimney), at a higher level than the bread oven connection.

\section{Conclusions}

Computerized fire modeling must be used as a tool of major importance in the technicalscientific and forensic analysis of these events. In the case of a post-event fire investigation, the task of creating virtual models and computer simulations is easier than in fire safety design engineering, as in most cases there is additional information on the event, from both witnesses involved, photo/video recordings captured by the surveillance cameras, as well as by the analysis of the evidence gathered from the crime scene, the firefighters' reports, etc.

One of the main uses of fire numerical modeling refers to hypothesis testing, an important step in the scientific investigation of the fire. Hypotheses can be developed not only to 
establish the causes of the event but also to determine the initial outbreak or place of initiation, respectively the circumstances that led or facilitated its occurrence. At the same time, by running multiple computer simulations for various scenarios, numerical models can contribute to the validation or rejection of statements, hypotheses or preconceptions. FDS, through the advanced facilities offered, is today an extremely popular analysis software tool, used successfully in researching these events.

The case study presented shows the importance of using numerical modeling and computer simulations in the laborious process of fire-type events investigation. The results obtained by the simulations were able to provide valuable information on the mechanism of initiation and further development of the fire, the distribution over time of the temperature and the concentration of carbon monoxide, at the level of the analyzed space. Based on these results, it was possible to substantiate the testing of the two hypotheses of the investigators regarding the cause and the way of initiation, as well as the choice of the final hypothesis.

\section{Acknowledgements}

This paper was developed within the Nucleu-Programme, carried out with the support of the Ministry for Research, Innovation and Digitalization, project no. PN-19-21-01.02, Development of institutional capability for technical expertise of fire type events for residential and industrial environments, by computerized simulation (in Romanian).

\section{References}

1. National Fire Protection Association, NFPA 921- Guide for Fire and Explosion Investigations (NFPA, Quincy, Massachusetts, 2021)

2. S. Calotă, G. Popa, G. Sorescu, S. Dolha, Practical research guide of fire causes -2 dn Ed. (in Romanian, Ed. Universul Juridic, București, 2016)

3. G.E. Gorbett, ISFI2008, Computer fire models for fire investigation and reconstruction (Cincinnati, Ohio, 2008)

4. A.C.Y. Yuen, G.H. Yeoh, B. Alexander, M. Cook, Build. Simul. 7(5), 477-487 (2014)

5. W. Jahn, O. Gonzales, J. de Dios Rivera, J.L. Torero, Forensic Science International, 1-33 (2015)

6. J. Lentini, Encyclopedia of Forensic Sciences (Wiley, pp.392-395, 2013)

7. K. McGrattan, S. Hostikka, J. Floyd, Fire dynamics simulator (Sixth Edition) User guide, (NIST Special Publication, 1019-6, 2019). 